\title{
Gravity-induced shear force in reinforced concrete walls above transfer structures
}

$1 \quad$ Tim On Tang BEng

PhD Candidate, Department of Civil Engineering, The University of Hong Kong, Hong Kong, PRC
2 Ray Kai Leung Su BSc(Eng), PhD, CEng, MIStructE, MHKIE, RPE(HK)

Associate Professor, Department of Civil Engineering, The University of Hong Kong, Hong Kong, PRC
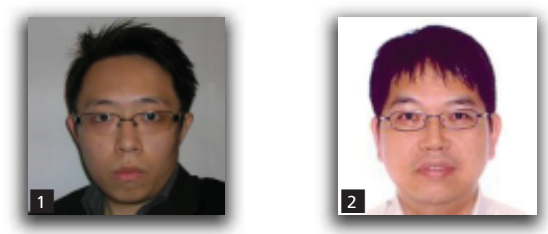

In this study, the gravity loads in reinforced concrete shear walls supported on transfer structures are investigated. Emphasis is placed on the shear-stress concentration effects on the supported shear walls owing to the distortion of the transfer structure. A simplified model is proposed to illustrate the fundamental physical interactions. Finite-element analysis is also conducted to study the influences of the symmetric and asymmetric shear-wall arrangements, positioning of supporting columns and span-to-depth ratio of the transfer structure. Non-linear behaviours encompassing the use of yielded stiffness at ultimate limit state, sequential construction and the creep of reinforced concrete under gravity loads are addressed. Various effects of modelling assumptions and simplifications on the stress redistribution of the transfer structure are investigated. Remedial measures are proposed, such as increasing the depth of the transfer girders using late-cast slabs, segmented upper shear walls and concrete of higher grade for critical regions.

\section{Notation}

$A_{i} \quad$ gross sectional area of the $i$ th wall

$A_{\mathrm{s}, i} \quad$ shear area of the $i$ th wall

$B \quad$ elastic compliance tensor

$b \quad$ breadth of the wall

$d \quad$ effective depth of the wall

$d_{i} \quad$ total depth of the $i$ th wall

E short-term elastic modulus

$E^{\prime \prime} \quad$ effective modulus accounting for creeping of RC

$f_{\mathrm{c}}^{\prime} \quad$ mean cylinder strength of concrete

$f_{\mathrm{ck}}$

$f_{\mathrm{cu}}$

G

I

$L$

$M_{i}$

$N_{i}$

characteristic cylinder strength of concrete

characteristic cube strength of concrete

short-term shear modulus

gross moment of inertia

clear span of the transfer structure

moment load on the $i$ th wall

axial load on the $i$ th wall

total number of columns/walls in a storey

linear algebraic relaxation function

days elapse since first loading

days when first loading is applied

shear load on the $i$ th wall

ageing coefficient
40

Downloaded by [ University of Hong Kong] on [14/08/16]. Copyright @ ICE Publishing, all rights reserved.

\author{
strain tensor \\ initial strain at the time of first loading \\ stress tensor \\ bending stress on the extreme fibre of the wall \\ average normal stress of all walls on a storey \\ average shear stress on the wall \\ creep coefficient
}

\section{Introduction}

High-rise buildings have become commonplace in developed and densely populated cities due to advances in building technologies over the last few decades. Among these buildings, transfer structures, which distribute vertical loading from shear walls above to widely spaced columns below through transfer girders or plates, have prevailed because they can accommodate the composite use of areas. However, critical shear stress and normal stress on shear walls can arise from deformed transfer structures under gravity loads. Such stress redistribution can result in severe shear and moment loads on the supported shear walls with magnitudes comparable to resultant forces under wind or seismic loads. Without conducting the appropriate analysis of the full transfer structure model, this fact could be overlooked by practising engineers who have no prior knowledge of such effects. 
Owing to the complexity of interaction between the transfer structure and supported walls, the latest physical model available is still based on the former arching theory proposed by Macleod and Green (1973) and Stafford Smith and Riddington (1977) for directly supported shear walls with columns below the transfer structure. Such a physical model assumes that the gravity loads are transferred from the supported shear walls to columns below through primary and secondary compression arches formed within the shear walls and the transfer structure, whereas the transfer girder in connection with the supported shear wall is simplified as a rigid arm. The latter assumption is a typical simplification in the frame analysis, yet it violates the actual phenomenon ob- served in the detailed finite-element analysis. When relatively thin shear walls are supported above a transfer girder much wider than the thickness of the wall, significant curvatures can be observed even in cross-sections under the wall. Omission of the curvature of a transfer girder would result in underestimating the base rotations of the walls and the resultant stresses induced in the walls and the coupling beams and slabs. In addition, loads from walls supported on a cantilever transfer girder are seldom transferred in the same way as a compression arch. Figure 1 shows some typical shear cracks on exterior walls and tension cracks on a slab and a coupling beam just above transfer structures, which cannot be explained by the existing arching
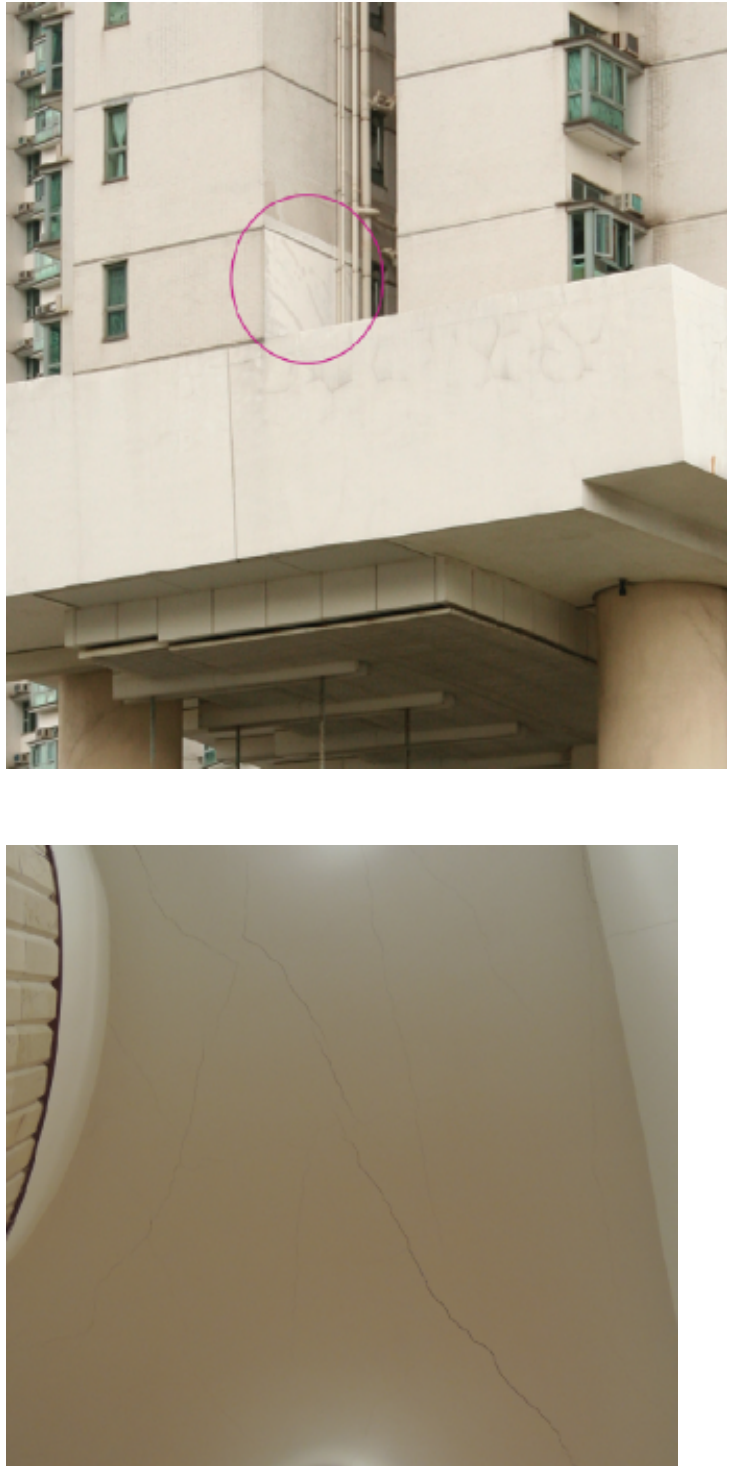

Figure 1. Cracked wall, slab and beam sections above the transfer level: (a) cracked walls above cantilevered transfer structures and (b) tension cracks on a slab and a coupling beam above the transfer level

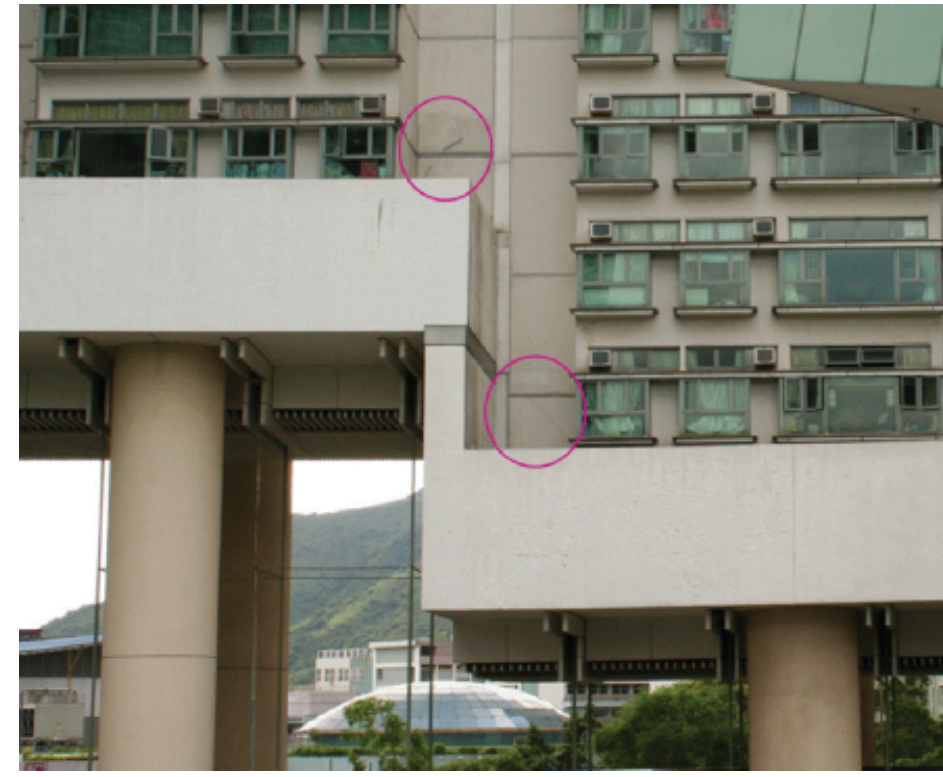

(a)

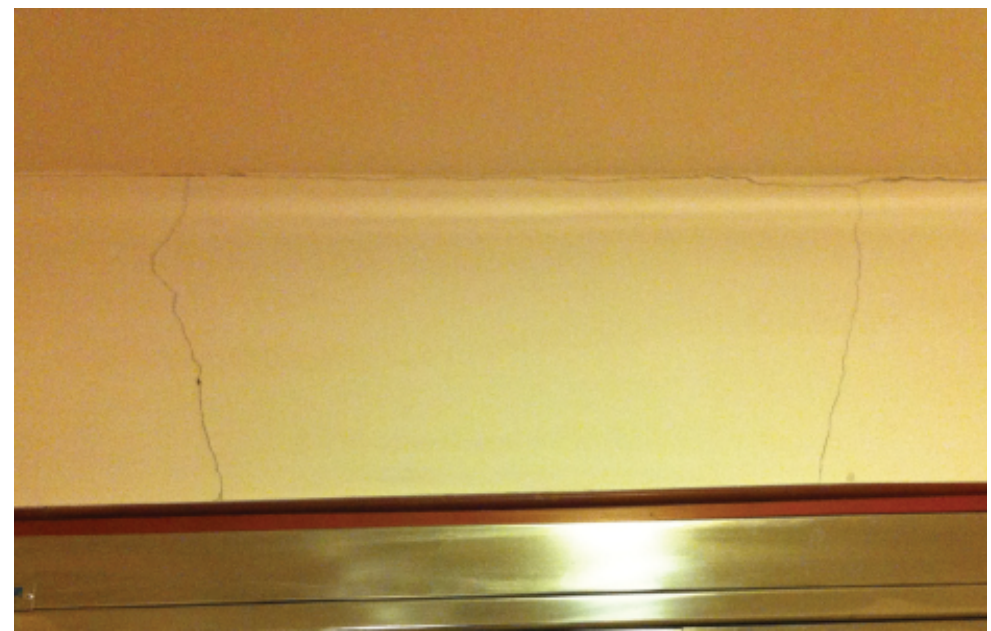

(b) 
theory. Apart from thermal or shrinkage cracks, these extensive cracks on normal-sized reinforced concrete (RC) walls, beams and slabs under service are likely attributed to shear and bending concentrations in improperly designed structures. Precautions to control thermal and shrinkage cracking in bulky transfer structures have been discussed in various studies (e.g., Liu and Wang, 2009; Man, 2010). However, possible improper designs have rarely been mentioned. In these adverse circumstances, large induced shear loads could even dictate the structural design when the loads are combined with wind or seismic loads $\mathrm{Su}$ and Cheng, 2008).

To quantify the stress concentration effect on coupled shear walls above a transfer structure, analogous physical models, such as a coupled shear wall supported on a flexible basis, have been reviewed. The study was first conducted by Coull (1971), who treated the vertical and rotational base flexibility separately by vertical and rotational springs. Based on the continuum approach for laterally loaded coupled shear walls, a closed-form solution was obtained by superimpositions of these results, which incorporates the foundation-structure interaction. Coull and Chantaksinopas (1974) extended the study to include symmetric coupled shear walls resting on an elastic foundation or above a portal frame hinged to a rigid ground. The latter model is more relevant to the current issue; yet, there are inherent assumptions including the fact that all the derivations are based on a laterally loaded system and that the point of contraflexure is formed at the mid-span of transfer girders. Obviously, this is not applicable to a gravity loaded system. Other similar studies have been conducted by various researchers such as Toutanji (1997) and Choo and Li (1997), who have respectively accounted for the base deformations of walls in the frame-wall system and the multi-stiffened coupled shear wall system. Latest developments have extended to studies of elasto-plastic behaviour using the discrete force method and assuming that plasticity is restricted to the coupling beams (Nadjai and Johnson, 1998). Those studies simulated the foundation-structure interaction by assigning separate vertical and rotational springs to the base of walls; their stiffnesses are associated with the ground properties. Not only is the constant stiffness assumed for soil grounds not applicable to transfershear wall interaction, as its stiffness depends on supporting transfer structures and varies along the position of the shear wall, but the difference in base rotational angles of adjacent walls also leads to a more significant shear concentration effect, which has been neglected in the aforementioned studies for the sake of simplicity (Coull, 1971; Toutanji, 1997). As coupled shear walls are mainly designed to resist lateral wind and seismic loads, most studies emphasise the lateral loads effect or the determination of the free vibration periods for seismic analysis (e.g., Vuddandam et al., 2013). Kuang and Zhang (2003) conducted parametric studies to evaluate the stress concentration effect under gravity loads; however, these studies were limited to a continuous wall supported above the transfer structures, and the analysis was focused on uneven axial stress

distributions along the wall-transfer interface. As a result, the shear stress concentrations on wall-transfer interaction owing to gravity loads are worth examining.

In this study, a comprehensive physical model describing the contribution of the slab and beams above the transfer structure and the deformed shapes of the adjacent columns and walls is proposed to illustrate the interaction effect of the transfer structure under in-plane gravity loads. Critical parameters contributing to the shear stress concentration are outlined and examined using parametric studies of numerical models. By comparing the average shear stresses induced on the wall-transfer interface in different situations, remedial actions in terms of revising the structural layouts and improving the modelling techniques are suggested as a design reference to practising engineers.

\section{Formation of shear concentration under gravity loads}

The presence of stiff and massive transfer structures can affect the displacement responses of a building under lateral or gravity loads. An abrupt change in the inter-storey drift and shear loads on the walls often occurs in the vicinity of the transfer level. Many engineers may ignore the out-of-plane deformations of the transfer plate, larger than the walls they support, and adopt rigid plate and rigid diaphragm assumptions in gravity load or lateral load calculations. However, such local deformations are the primary cause of the abrupt change in shear in exterior walls and should not be neglected in gravity load and lateral load analyses.

The effect of shear concentration on the transfer structure under lateral loads has been discussed by $\mathrm{Su}$ and Cheng (2008). The out-of-plane deformation of the transfer plate could result in shear concentration on the exterior walls above transfer structures. Figure 2 illustrates hogging and sagging deformations generated in the transfer structure owing to gravity loads.
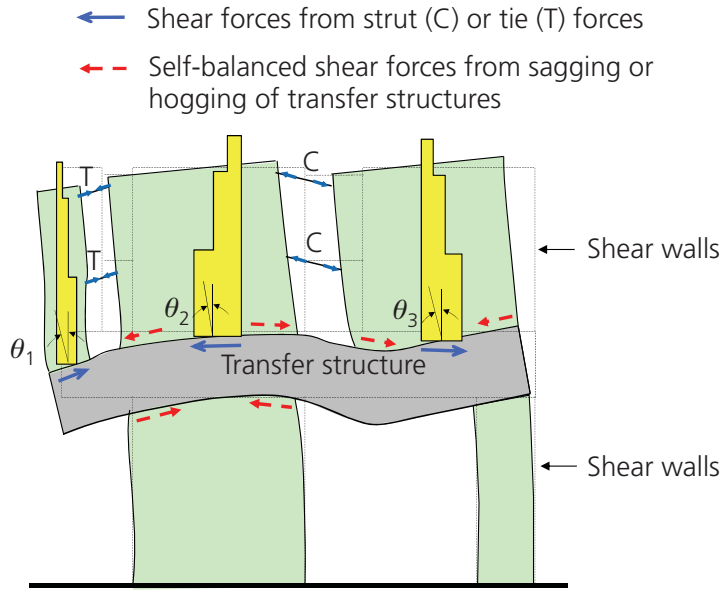

Figure 2. Local deformations and shear concentration of a transfer structure owing to gravity loads 
Relatively thin shear walls cannot constrain the out-of-plane deformation of transfer plate effectively. As the shear walls are connected monolithically to the transfer structure, the walls and transfer plate deform together at the wall-transfer structure interfaces owing to the displacement compatibility. Hogging or sagging curvatures of the transfer beams in plans parallel to the walls can elongate or shorten the cross-sectional depth of walls, which can be explained as follows: assume that the wall is $300 \mathrm{~mm}$ thick and the transfer beam is $1000 \mathrm{~mm}$ wide, as in the example that will be later referred to in Figure 3. In this situation the wall-transfer structure interface is not sufficiently rigid to resist the gravity loads without forming curvature on the transfer girder in plans parallel to the plan of the wall. Such curvature results in generating some local stresses on the ends of the walls due to displacement compatibility in the transversal direction. A pair of almost self-balanced shear forces (indicated as grey arrows in Figure 2) could be developed in each wall. Furthermore, the joint of the transfer structure and the wall is rotated in a similar manner. The walls at the transfer level rotate by different degrees and in different directions as vertical cantilevers. However, as the horizontal movements of walls above the transfer levels are constrained by floor slabs and coupling beams, in-plane compressive or tensile restraining forces are generated in the slabs and beams. These horizontal reactions (indicated as black arrows in Figure 2) transmitted from one wall to the other walls are the origin of the abrupt change of shear forces and the shear concentration near the transfer level.

The above physical model indicates the amount of horizontal reaction generated depends on the lateral stiffnesses of the walls and the differences between their base rotations. Shear failure may occur in exterior walls, especially when it is offset from the support below at a significant distance. Moreover, slabs can be impaired by the high tensile stresses when the connecting walls rotate in the opposite direction. These predictions coincide with the observed cracks that occur in buildings with a cantilever transfer structure, as shown in Figure 1. As a consequence of the shear concentration effect, it is crucial to check the shear capacity of the walls and the shear demands to avoid unintentional shear failure of the walls. Nonetheless, the provisions for shear design, and in particular to the walls, are not well elaborated upon in most codes of practice. For comparison, the ultimate allowable design shear strength for RC columns and walls stipulated in Eurocode 2 (BS EN 1992-1-1, BSI, 2004), American Standards (ACI 318-11 (ACI, 2011)), New Zealand Standards (NZS 3101 (SNZ, 2006)), Canadian Standards (CSA A23.3-04 (CSA, 2004))

\begin{tabular}{l}
\hline Basic dimensions \\
\hline Thickness of walls $=300$ \\
Size of coupling beams $=300 \times 400 \mathrm{dp}$ \\
Size of transfer girder $=1000 \times 2000 \mathrm{dp}$ \\
Size of columns $=1000 \times 2000 \mathrm{dp}$ \\
Size of slabs $=4000 \times 170 \mathrm{dp}$ \\
N.B. All units are in millimetres \\
\hline
\end{tabular}

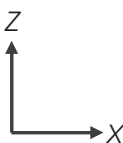

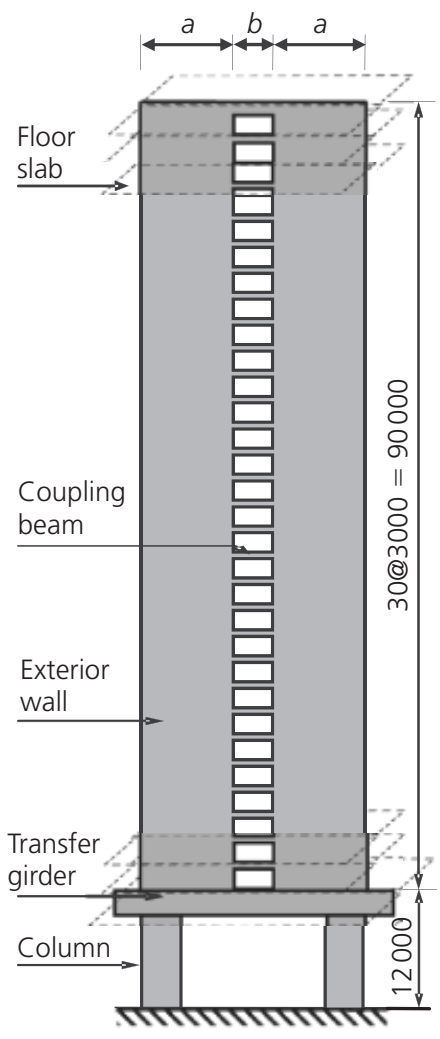

(a)

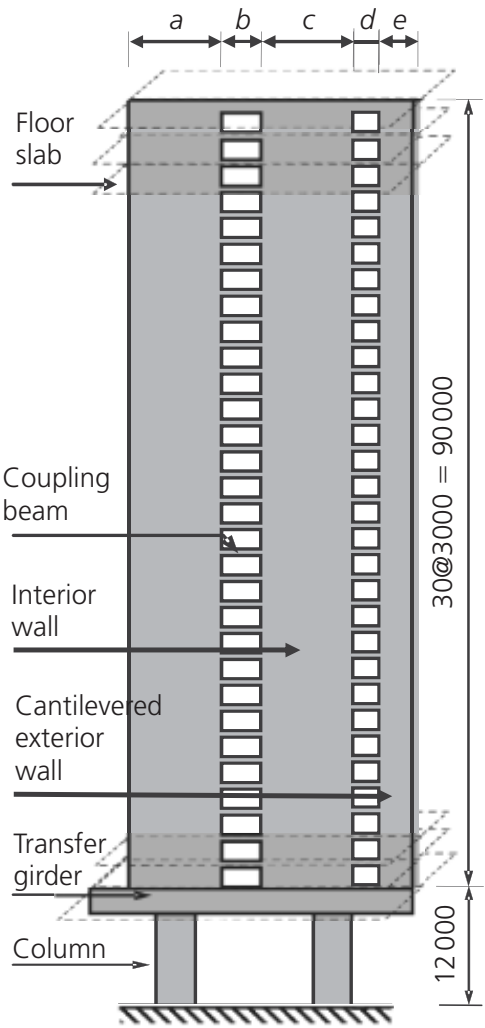

(b)

Figure 3. Typical structural arrangements of the numerical model: (a) model A with a symmetrical layout and (b) model B with an exterior wall on the cantilever girder support 
and the earlier British Standards (BS 8110 (BSI, 1997)) are summarised in Table 1. This design limit is codified to primarily guard against diagonal compression failure of the concrete strut in the truss analogy. Table 2 shows the shear stress limits for different concrete grades using the codified design equations, which increase with concrete grade and are limited to approximately 4 to $5 \mathrm{MPa}$ by most codes of practice.

When extensive parametric studies are conducted, the critical interfacial shear stress on the wall-transfer joint can often reach $2 \mathrm{MPa}$ or more. As a result, a considerable amount of interfacial shear stress has to be accounted for in the shear wall design even before the wind or seismic loads are introduced. This illustrates the significance of investigating this physical phenomenon.

In the following sections, finite-element models simulating the inplane loaded shear walls above a transfer structure under gravity loads are presented. Factors influencing the shear concentration effect will be investigated. Thus effective alternatives can be identified to mitigate the shear concentration problem under gravity loads.

\section{Computational modelling}

To illustrate the shear stress concentration for upper shear walls and quantify various factors influencing such effects, two typical layouts of coupled shear walls on transfer girder models, as shown in Figure 3, are considered in the analysis. In the first model, two shear walls, coupled by beams and slabs, are

\begin{tabular}{|c|c|c|c|c|c|c|}
\hline Concrete grade & C35 & C40 & C45 & C50 & C55 & $\mathrm{C} 60$ \\
\hline$f_{\mathrm{cu}}: \mathrm{MPa}$ & 35 & 40 & 45 & 50 & 55 & 60 \\
\hline$f_{\mathrm{ck}}=0.8 f_{\mathrm{cu}}: \mathrm{MPa}$ & 28 & 32 & 36 & 40 & 44 & 48 \\
\hline \multicolumn{7}{|c|}{ Maximum design shear stress limit: MPa } \\
\hline BS 8110 (BSI, 1997) & $4 \cdot 7$ & $5 \cdot 0$ & $5 \cdot 0$ & $5 \cdot 0$ & $5 \cdot 0$ & $5 \cdot 0$ \\
\hline EC2 EN1992 (BSI, 2004) & $5 \cdot 0$ & $5 \cdot 6$ & $6 \cdot 2$ & $6 \cdot 7$ & $7 \cdot 3$ & $7 \cdot 8$ \\
\hline $\mathrm{ACl} 318-11(\mathrm{ACl}, 2011)$ & $3 \cdot 3$ & $3 \cdot 5$ & $3 \cdot 7$ & $3 \cdot 9$ & $4 \cdot 1$ & $4 \cdot 3$ \\
\hline $\begin{array}{l}\text { CSA A.23.3-04 (CSA, } \\
\text { 2004) }\end{array}$ & $4 \cdot 1$ & $4 \cdot 7$ & $5 \cdot 3$ & $5 \cdot 9$ & $6 \cdot 4$ & $7 \cdot 0$ \\
\hline NZS 3101 (SNZ, 2006) & $4 \cdot 2$ & $4 \cdot 8$ & $5 \cdot 4$ & $6 \cdot 0$ & $6 \cdot 0$ & $6 \cdot 0$ \\
\hline
\end{tabular}

Table 2. Maximum design shear strength of various concrete grades

supported by a frame with a transfer girder. The second model consists of an additional exterior wall situated on the cantilevered transfer girder. This mimics the adverse effect in particular to this exterior wall owing to reversed rotations induced at the bases of the walls above the deformed transfer girder.

Both building models are $102 \mathrm{~m}$ high, comprising 30 typical floors above a transfer girder with an elevation of $12 \mathrm{~m}$. Other basic dimensions of the models are shown in Figure 3 and Table 3. The material properties adopted in the analysis are shown in Table 4. Apart from the self-weight of $24.5 \mathrm{kN} / \mathrm{m}^{3}$ for the RC material, a superimposed dead load of $6 \mathrm{kPa}$ and a live load of

\begin{tabular}{|c|c|}
\hline Codes of practice & Shear limit for RC columns and walls \\
\hline $\begin{array}{l}\text { BS } 8110 \\
\text { (BSI, 1997) }\end{array}$ & $\begin{array}{l}\text { The RC column follows beam shear design and is limited by the lesser of } 0.8 \sqrt{ } f_{\mathrm{cu}} \text { and } 5 \mathrm{MPa} \text { with a } \\
\text { material factor of safety (FOS) }=1.25 \text { considered, where } f_{\mathrm{cu}} \text { is the characteristic cube strength of concrete. } \\
\text { In contrast, there is no specific provision for the shear design of the wall. }\end{array}$ \\
\hline $\begin{array}{l}\text { EC2 EN1992 } \\
\text { (BSI, 2004) }\end{array}$ & $\begin{array}{l}\text { The shear strength design of all RC members is limited to } 0 \cdot 2\left[1-f_{\mathrm{ck}} / 250\right] \times f_{\mathrm{ck}} \text {, where } f_{\mathrm{ck}} \text { is the } \\
\text { characteristic cylinder strength of concrete in MPa. A material FOS }=1.5 \text { is considered under transient } \\
\text { loads. }\end{array}$ \\
\hline $\begin{array}{l}\mathrm{ACl} 318-11 \\
(\mathrm{ACl}, 2011)\end{array}$ & $\begin{array}{l}\text { A special provision for shear design in walls is specified. The maximum shear stress is limited to design } \\
\text { strength }=0.83 \sqrt{ } f_{\mathrm{ck}} \times \phi \text {, where } \phi=0.75 \text { is the strength reduction factor for shear (i.e., the material } \\
\text { FOS }=1.33 \text { for shear); } \sqrt{ } f_{\mathrm{ck}} \text { should not exceed } 8.3 \mathrm{MPa} \text {. The provision for beams and columns is similar to } \\
\text { the above design value for non-prestressed members, without consideration of the axial load effect on the } \\
\text { concrete shear strength. }\end{array}$ \\
\hline $\begin{array}{l}\text { CSA A23.3-04 } \\
\text { (CSA, 2004) }\end{array}$ & $\begin{array}{l}\text { For non-prestressed members, the maximum design shear stress } V_{r \text {, max }} \text { shall not exceed } 0.225 f_{c k} \times \phi_{c} \text {, } \\
\text { where the shear cross section defined by effective shear depth } d_{v}=0.9 d \text { is considered, and } \phi_{c} \text { is the } \\
\text { resistance factor for concrete }=0.65 \text { (i.e., the material FOS }=1.54 \text { ). }\end{array}$ \\
\hline $\begin{array}{l}\text { NZS } 3101 \\
(S N Z, 2006)\end{array}$ & $\begin{array}{l}\text { For column and pier design, the maximum design shear stress shall not exceed } 0.2 f_{\text {ck }} \times \phi \text { or } 8 \times \phi \mathrm{MPa} \text {, } \\
\text { where } \phi \text { is the strength reduction factor }=0.75 \text { (i.e., the material FOS }=1.33 \text { for shear). }\end{array}$ \\
\hline
\end{tabular}

Notes: The strength reduction factor in $\mathrm{ACl}$ and NZS accounts for (a) the possible under-strength of members, $(b)$ inaccuracies in design equations, (c) the importance and degree of ductility and reliability of members.

Table 1. Probable maximum design shear strength of RC columns

and walls 


\begin{tabular}{lccccccc}
\hline Model & \multicolumn{3}{c}{ Wall length } & & \multicolumn{2}{c}{ Coupling beam length Total length: $m$} \\
\cline { 2 - 3 } & a: $m$ & C: $m$ & e: $m$ & & b: $m$ & d: $m$ & \\
\hline A & 6 & N.A. & N.A. & & 2 & N.A. & 14 \\
B & 6 & 5 & 2 & & 2 & 1 & 16
\end{tabular}

Table 3. Dimensions of models

\begin{tabular}{lc}
\hline Property & Value \\
\hline Concrete grade & $45 \mathrm{MPa}$ \\
Poisson ratio & $0 \cdot 2$ \\
Modulus of elasticity $(E)$ & $26 \cdot 4 \mathrm{MPa}$ \\
Table 4. Material properties of models & \\
\hline
\end{tabular}

$2 \mathrm{kPa}$, representing the typical loading on residential buildings, are adopted in the analysis. The resulting floor mass density of $5.89 \mathrm{kN} / \mathrm{m}^{3}$ is comparable to $5 \cdot 5 \mathrm{kN} / \mathrm{m}^{3}$, which is the average density of typical residential blocks sampled in Hong Kong ( $\mathrm{Su}$ et al., 2003).
Owing to the complexities of the interaction between the supported shear walls and the transfer girder, the finite-element program Etabs (CSI, 2005) is employed for the analysis. Figure 4 shows the configuration of the models, in which shell elements are adopted for modelling support columns, upper shear walls, the transfer girder and slabs, while the coupling beams are modelled by frame elements. The shell elements are quadrilateral plane-stress elements with a constant mesh size of $250 \mathrm{~mm}$. This discretisation was considered to yield accurate results, as reduction in the mesh size by $20 \%$ results in variations of less than $1 \%$ on the calculated shear and moment loads at the critical wall sections in models A and B.

Variables that influence the shear concentration effect comprising wall locations, depth of transfer girder and various modelling simplifications are considered in the present study. Non-linear

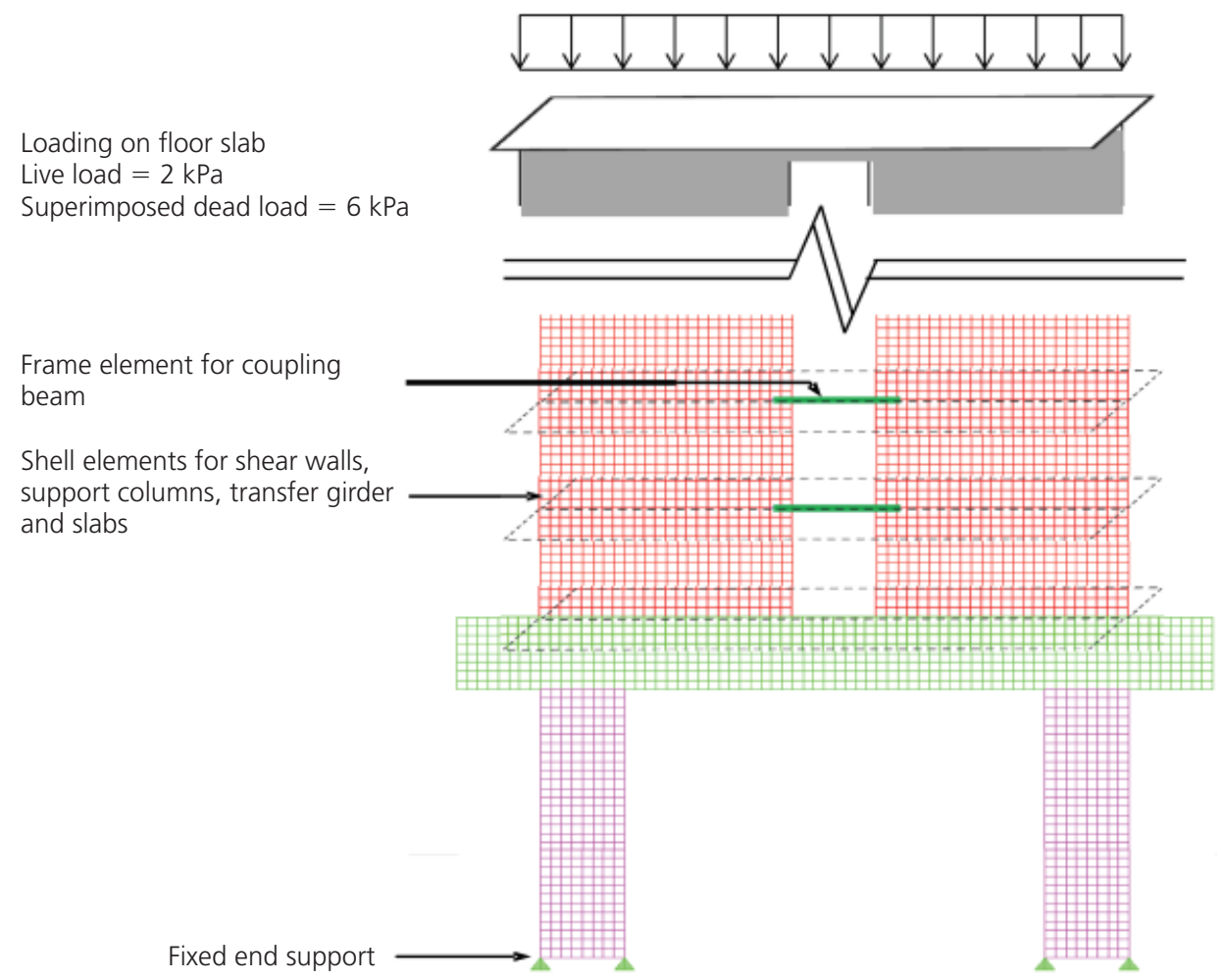

Figure 4. Finite-element model for coupled shear walls above the transfer girder 
influences by the cracked sections, the stages of construction and the creeping of RC are discussed in Sections 4.6 and 4.7.

\section{Results and discussions}

\subsection{Shear concentration on shear walls}

Under long-term service loads, the vertical deflection-to-span ratio for the transfer girder in model $\mathrm{A}$ and model $\mathrm{B}$ conforms well to the permissible deflection limit of $1 / 480$ for slabs, so as to avoid impairing any supported non-structural components (Table 9.5(b) of ACI 318-11 (ACI, 2011)). To assess the shear concentration on the walls and columns under the ultimate limit state, a shear concentration ratio (SCR) is defined in Equation 1

1.

$$
\mathrm{SCR}_{i, j}=\left[\frac{V_{i} / A_{\mathrm{s}, i}}{\left(\sum_{i=1}^{n} N_{i}\right) /\left(\sum_{i=1}^{n} A_{i}\right)}\right]_{j \text { thfloor }}
$$

2. $\mathrm{SCR}_{i, j}=\left[\frac{\sigma_{V, i}}{\sigma_{N, \text { total }}}\right]_{j \text { thfloor }}$

where $N_{i}$ and $V_{i}$ are, respectively, the axial and shear loads on the $i$ th wall, $A_{i}$ denotes the gross sectional area and $A_{\mathrm{s}, i}$ denotes the shear area equal to the product of the breadth $(b)$ and the effective depth $(d)$ of the wall. Alternatively, the SCR can be expressed as a dimensionless ratio of the shear stress $\left(\sigma_{V, i}\right)$ on the $i$ th wall to the average normal stress $\left(\sigma_{N, \text { total }}\right)$ of the total $n$ number of walls on the $j$ th floor. It is defined at different levels along the building height. The effective depth for the wall is further assumed herein as 0.8 times the total depth of the wall $\left(d_{i}\right)$, which is recommended by ACI 318-11 (ACI, 2011) for preliminary assessments without a strain compatibility analysis of the section. Similarly, the warping of transfer structure induces in-plane moments on the supported walls. It is expressed as a bending concentration ratio (BCR), of which the bending stress on the extreme fibre $\left(\sigma_{M, i}\right)$ is normalised by the average normal stress, $\sigma_{N \text {,total }}$, provided that the elastic plane section is assumed. Hence, the BCR can be presented as Equation 3 or Equation 4.

3.

$$
\mathrm{BCR}_{i, j}=\left[\frac{6 M_{i} / b d_{i}^{2}}{\left(\sum_{i=1}^{n} N_{i}\right) /\left(\sum_{i=1}^{n} A_{i}\right)}\right]_{j \text { thfloor }}
$$

$$
\text { 4. } \mathrm{BCR}_{i, j}=\left[\frac{\sigma_{M, i}}{\sigma_{N, \text { total }}}\right]_{j \text { thfloor }}
$$

in which $M_{i}$ is the moment load on the $i$ th wall and $d_{i}$ denotes the depth of the section. Similarly, the BCR can be expressed as a dimensionless ratio of the bending stress $\left(\sigma_{M, i}\right)$ on the $i$ th wall to the average normal stress $\left(\sigma_{N, \text { total }}\right)$ of all walls and columns on the $j$ th floor. Presuming all supported walls share similar axial stresses and the gravity load is transferred through a $45^{\circ}$ inclined strut developed in the wall and transfer girder, the maximum induced shear stress would likely be limited by $1 / 0 \cdot 8=1.25$ from Equation 1, where the factor 0.8 accounts for the effective shear area. The value of the SCR normally varies from 0 to $1 \cdot 25$, a larger value indicating the severity of shear concentration on that particular wall; the BCR may vary from 0 for no bending concentration on the wall to 2 or above for critical cases.

The height-wise distributions of the SCRs and BCRs on the wall and column for model A are depicted in Figure 5. Owing to the symmetric geometry and gravity loads, equivalent results for only one of the walls and columns are presented. The average normal stress on the transfer level under a factored gravity load, $\left[\sigma_{N, \text { total }}\right]_{1 / \mathrm{F}}$, is approximately $11 \mathrm{MPa}$, which is equivalent to an axial load ratio $\left(=N_{i} / A_{i} f_{\text {ck }} \approx \sigma_{N, \text { total }} / f_{\text {ck }}\right)$ of 0.3 for a $\mathrm{RC}$ wall made up of $\mathrm{C} 45$ concrete $\left(f_{\mathrm{cu}}=45 \mathrm{MPa}\right)$, where $f_{\mathrm{cu}}$ and $f_{\mathrm{ck}}$ $\left(\approx 0.8 f_{\text {cu }}\right)$ denote the characteristic cube and cylinder strength of concrete in MPa, respectively. For brevity the SCRs and BCRs of various floors are calculated using $\sigma_{\mathrm{N}, \text { total }} 1 / \mathrm{F}$. The SCRs and BCRs increase from 0 at the fourth storey above the transfer level to the largest values of $0 \cdot 34$ and $1 \cdot 4$, respectively, at the first storey. This result implies that a maximum average shear stress of $11 \times 0.34=3.8 \mathrm{MPa}$ is acting on the upper shear wall which results from solely gravity loads. A maximum bending stress equal to $11 \times 1.4=15.5 \mathrm{MPa}$ is also acting on the extreme fibre of the wall section at the first storey. It should be noted that this critical shear stress demand can take up almost $70 \%$ of the maximum allowable design strength stipulated by most of the standards, as shown in Table 2. For the columns below the transfer level, the stress concentration effect diminishes from the top to bottom interfaces of the column, where the stress demands are relatively trivial. The results demonstrate that the shear concentration effect is severe but will be limited to a few storeys above the transfer level. The shear concentration zone could be associated with the deflection profile or the clear span, $L$, of the transfer structures. In order to study the intensity of the stress concentration on walls under various structural arrangements, maximum SCRs and BCRs induced at the wall-transfer interface are compared in the following study.

\subsection{Shear concentration effect with varied support locations}

In this section, the influence of the locations of the supporting columns on the SCR and BCR is studied. The locations of both supporting columns for model A and only the right side column in model B are altered to simulate various support conditions. Figure 6 depicts the variations of SCRs and BCRs for the walls and columns in model A. At the concentric support condition, where the offset distance $=0 \mathrm{~m}$, the SCR and BCR are almost completely suppressed, indicating the optimal support conditions. Not surprisingly, when the supporting columns are shifted 


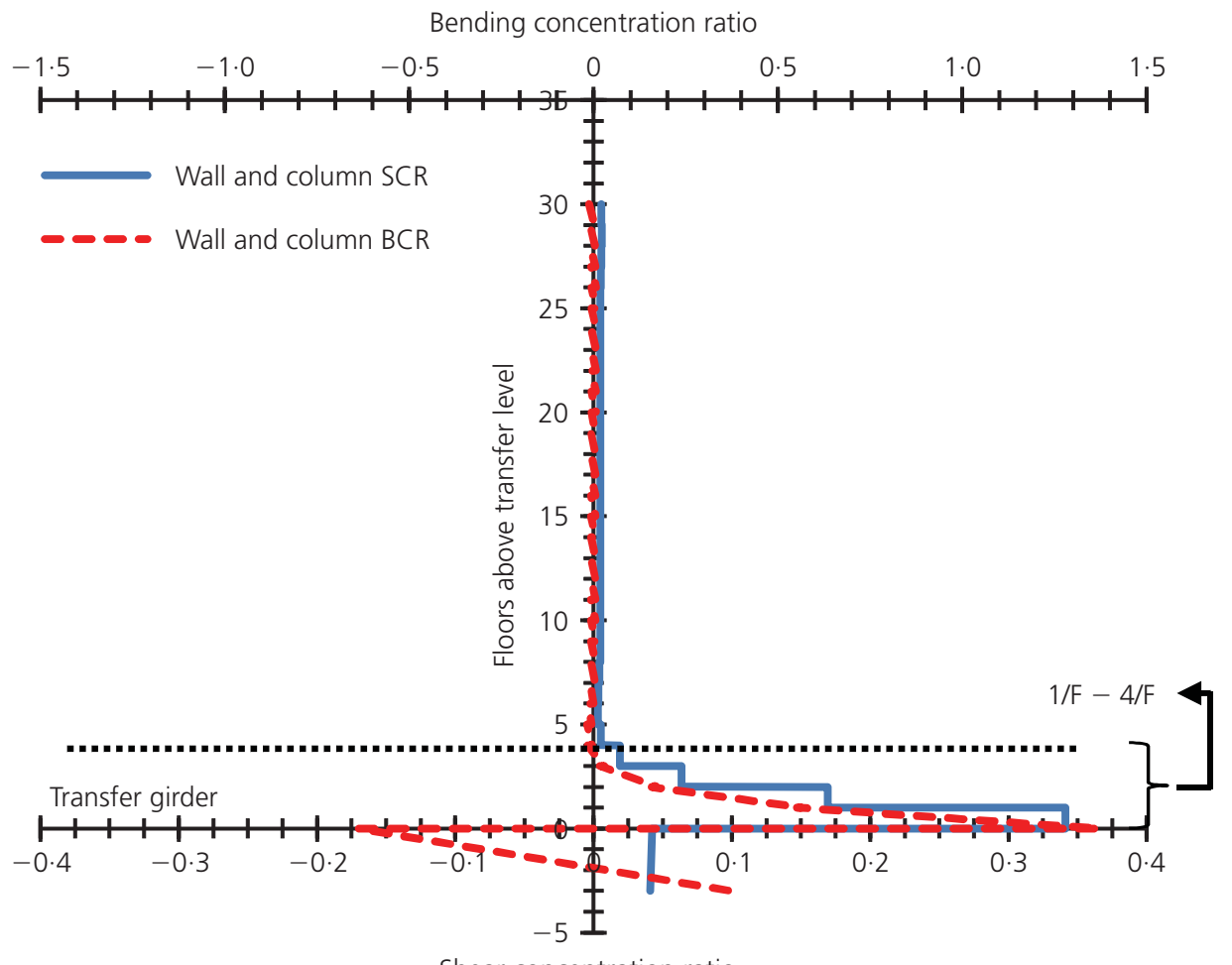

Shear concentration ratio

Figure 5. Vertical distributions of shear and bending concentration ratios for model $\mathrm{A}$

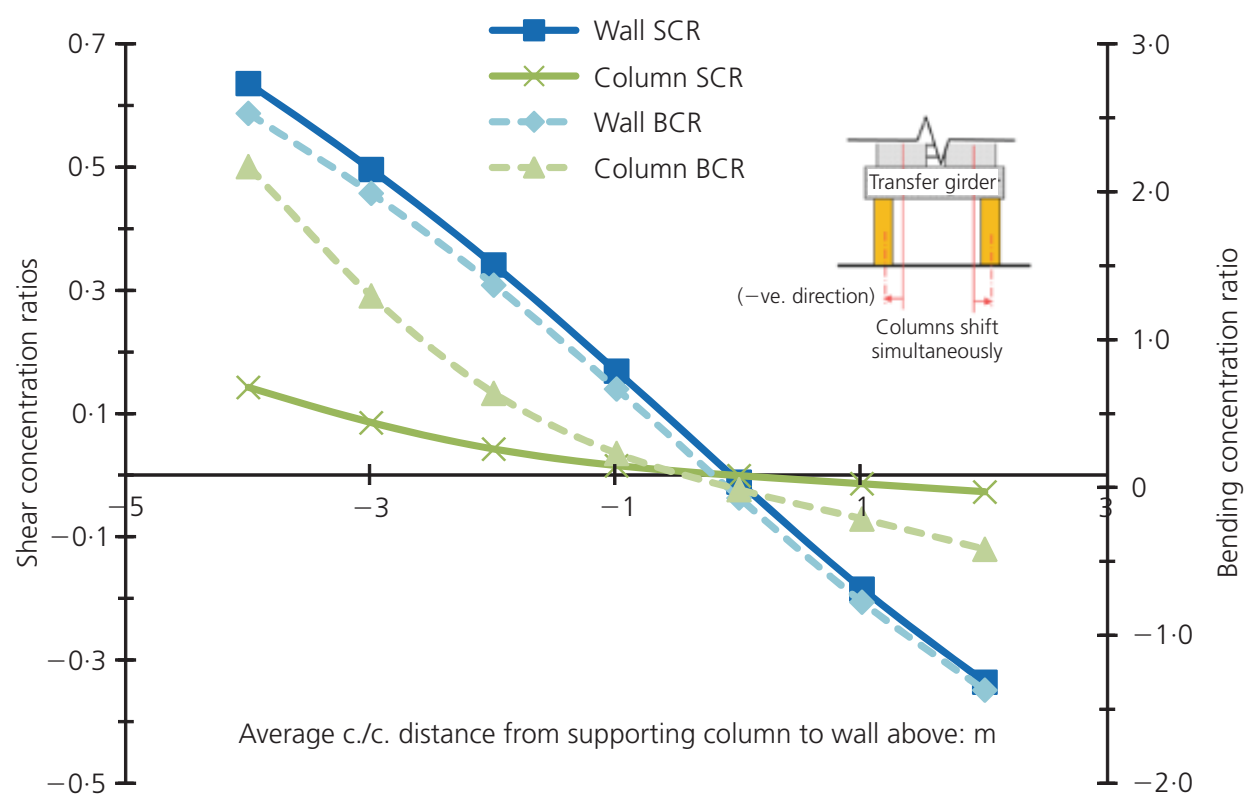

Figure 6. The variations of shear and bending concentration

ratios against the locations of supporting columns for model $A$

symmetrically, the SCR and BCR for walls and columns increase with larger offset distances in either direction. It should be noted that the increasing rates of the SCR and BCR are almost the same, such that the shear span ratio is close to a constant $\left(M_{i} / V_{i}\right)$ with all offset distances. The most critical SCR and BCR are $0.64\left(\sigma_{V, i}=7 \cdot 2 \mathrm{MPa}\right)$ and $2 \cdot 5\left(\sigma_{M, i}=28.6 \mathrm{MPa}\right)$, respectively, when the offset distances for both walls are at $-4 \mathrm{~m}$ (clear span of column supports $=14 \mathrm{~m}$ ). Even for a moderate offset dis- 
tance $=-1 \mathrm{~m}$ (clear span of column supports $=8 \mathrm{~m}$ ), the corresponding SCR and BCR are $0.17\left(\sigma_{V, i}=1.9 \mathrm{MPa}\right)$ and 0.67 $\left(\sigma_{M, i}=7.5 \mathrm{MPa}\right)$, respectively. With the support being shifted further inward, reversed shears and moments are induced on the walls and columns.

To minimise the stress concentration effect, the optimised location is the concentric support condition if there exists the same number of supports as the upper shear walls, such as in model A. However, it is more complex if there are fewer supports than the supported shear walls, as in model B. Figure 7 presents the variations of SCRs and BCRs for the interior wall and the cantilevered exterior wall (labelled in Figure 3) as a function of the offset distance of the right side column from that exterior wall. The optimised location for the minimum shear load is neither the concentric support conditions for the two walls (offset $=0 \mathrm{~m}$ and $4.5 \mathrm{~m}$ ) nor the average of the two (offset = $2.25 \mathrm{~m}$ ); it is at an offset distance close to $1.5 \mathrm{~m}$. Nevertheless, the stress concentration effect cannot be completely eliminated as in model $\mathrm{A} ; \mathrm{SCR}=0.15\left(\sigma_{V, i}=1.7 \mathrm{MPa}\right)$ remains on the inner wall. For other support conditions, the severe stress concentration on the cantilevered exterior wall can reach as high as $\mathrm{SCR}=0.25\left(\sigma_{\mathrm{V}, i}=3.0 \mathrm{MPa}\right)$. When the support is between the interior and cantilevered exterior walls with an offset distance from 2 to $4 \mathrm{~m}$, reversed shear and moment loads are induced on the walls. The loads are attributed primarily to the actions and reactions formed when the walls rotate and deflect away in opposite directions above the deformed transfer girder. Since floor slabs and beams just above the transfer tend to restrict such deformation, critical tensile forces could develop. These explain the extensive cracks observed on the walls and slabs in Figure 1.

\subsection{Shear concentration effect along the storey height}

Earlier studies (e.g., Su and Cheng, 2008) have indicated that the effect of shear concentration owing to the transfer plate deformations under lateral or gravity loads is restricted to a few storeys above the transfer level. The above observation coincides with the elevation plots of the SCR and BCR for model A in Figure 5. For model B, a comparison of the shear and bending concentration ratio along the building height above the transfer level is shown in Figure 8. It can be noted that opposite SCRs and BCRs are induced on the interior and cantilevered exterior walls. The stress concentration effect diminished rapidly against an increase in floor levels. It almost completely vanishes at the fourth storey above the transfer level. The above results support the assumptions made in deriving the physical model proposed in Section 2.

\subsection{Substitute model using gravity loads}

In practical design, the typical floors are often omitted in the building model for the gravity analysis. They are substituted by the equivalent gravity loads. Hence, any amendments to the building layouts can easily be catered for, making it possible to rerun the analysis in a limited amount of time. However, an inappropriate model simplification could result in significant errors. In this study, different numbers of the typical floors above the transfer level are substituted by loading, and the corresponding SCR and BCR for the upper shear walls at the first floor are compared in Figures 9 and 10, respectively. With more storeys modelled above the transfer level, it is shown that the results converge with the full model analysis, which is shown as dashed lines in the figures.

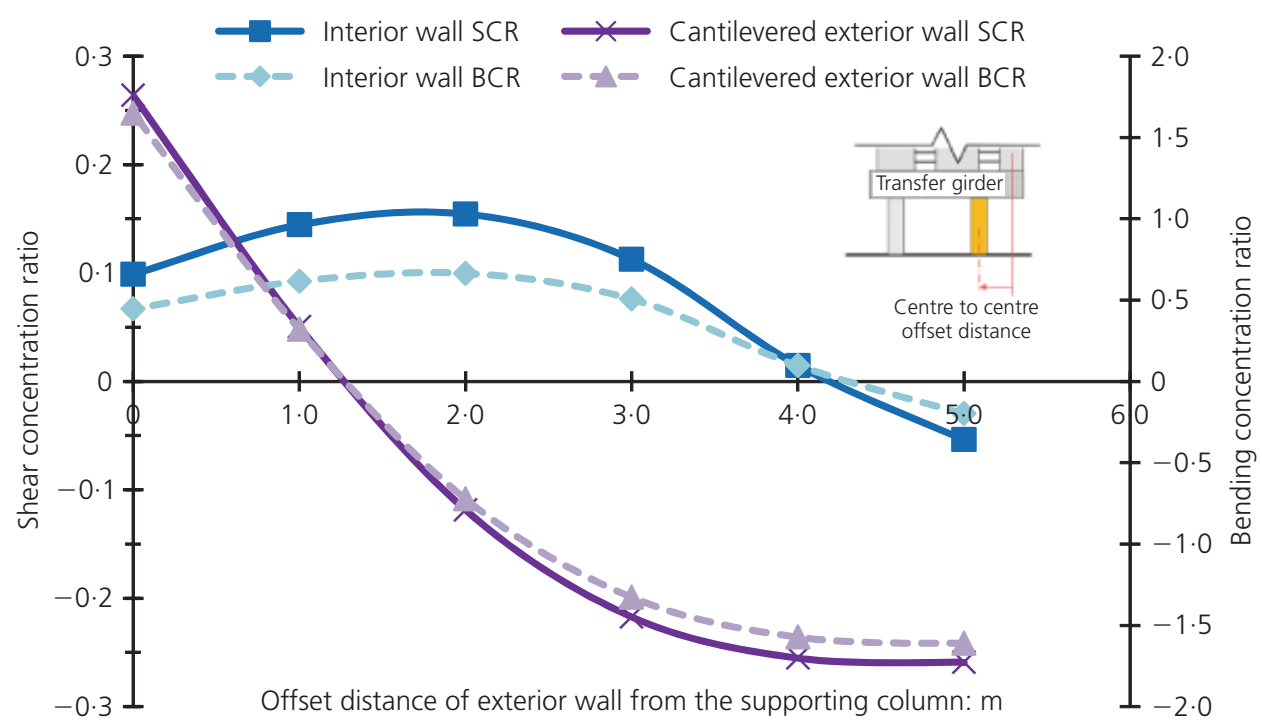

Figure 7. The variations of shear and bending concentration ratios against the offset distance of support for the cantilevered exterior wall in model $\mathrm{B}$ 


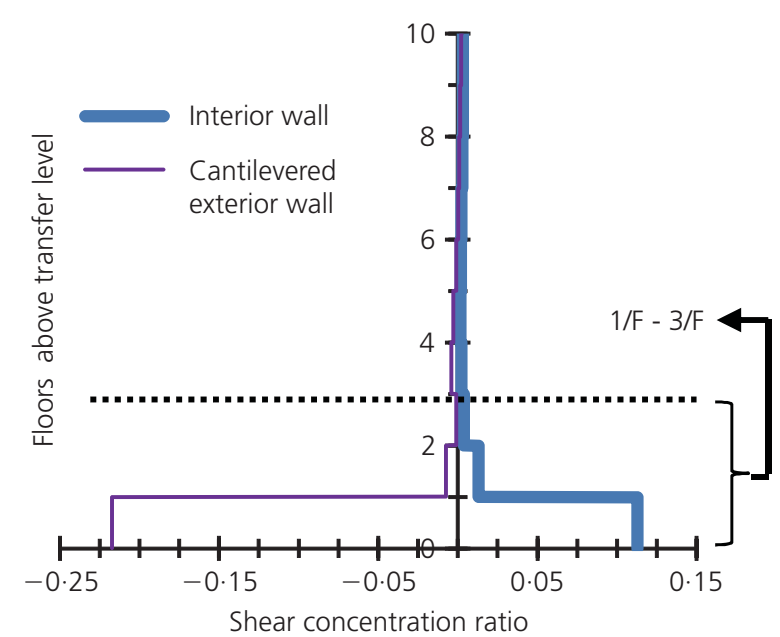

(a)

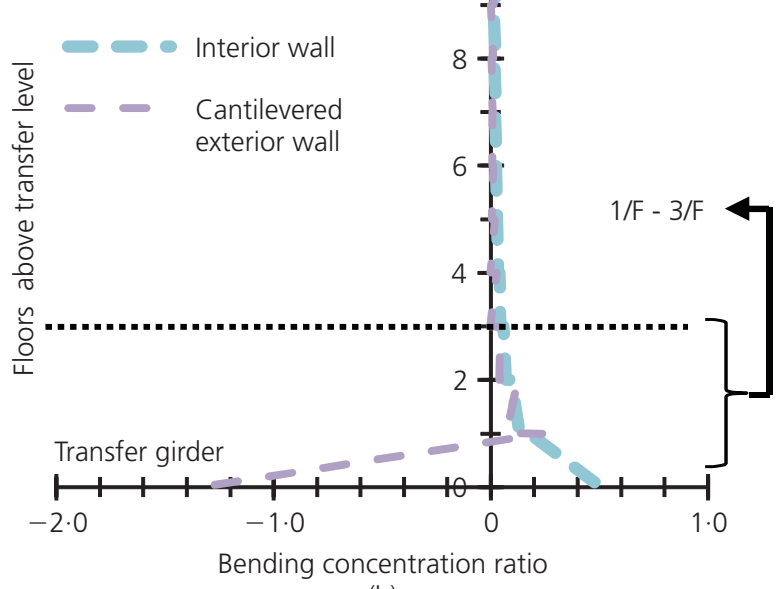

(b)

Figure 8. Vertical distributions of stress concentration ratios in (a) shear and (b) bending for model B

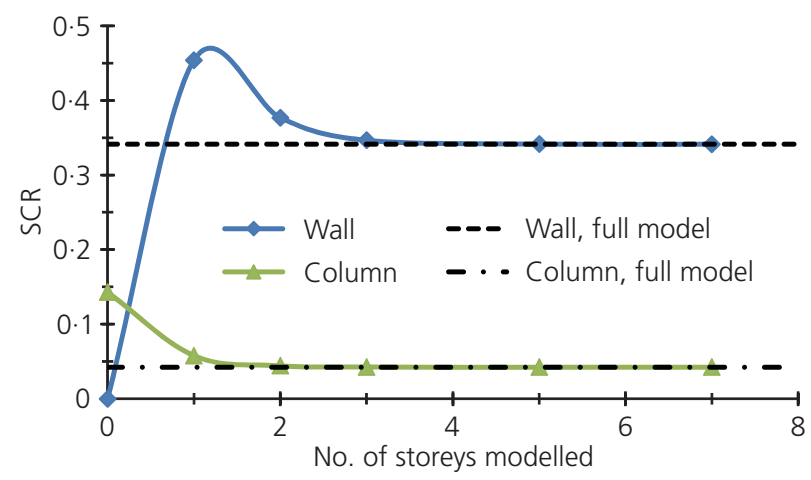

Figure 9. The variations of shear concentration ratios against the storeys modelled above the transfer girder for model A

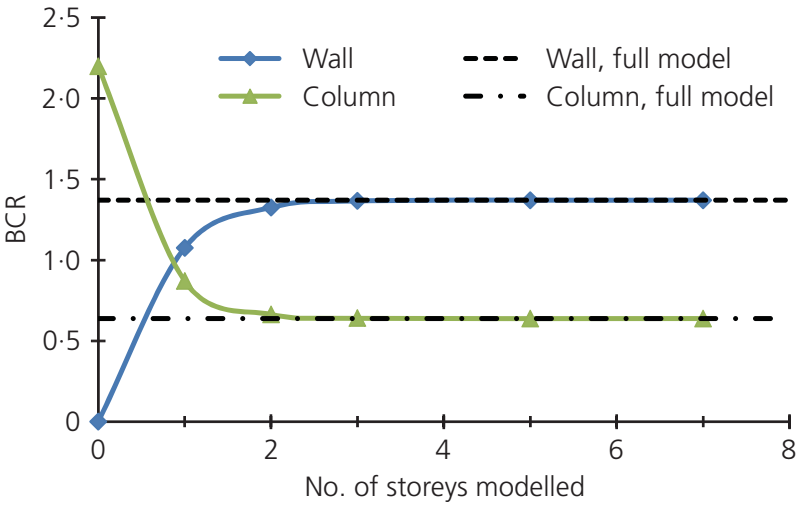

Figure 10. The variations of bending concentration ratios against the storeys modelled above the transfer girder for model A

In terms of load transfer, the omission of higher storeys above the transfer level results in shorter shear walls being modelled. As gravity loads are transmitted from the walls to the end column supports through the transfer girder, the concrete strut developed in the shear wall and transfer girder is also shortened. The smaller inclination angle of the strut to the horizontal leads to a less effective strut action. A higher SCR is induced to transmit the same amount of gravity load. In contrast, the complete omission of storeys above the transfer level inappropriately neglects the interacting strut or tie effect of floor slabs in higher storeys. The reduced moment arms outweigh the larger shear loads, leading to smaller base moments and an underestimated $\mathrm{BCR}$ in the upper shear walls. Comparatively, the BCRs on supporting columns are overstated by more than one time with no typical storey modelled. This is due to the less effective tie-andstrut action in transferring the loads from the upper shear walls to the end column, such that more loads are carried through the flexural beam action of the transfer girder, and the moment induced is carried down to the column. As a result, although typical floors above the transfer level could be simplified as equivalent gravity loads, at least two storeys above the transfer level should be modelled. The slabs and beams are essential for the interacting actions between walls above the transfer and should be modelled in the analysis.

\subsection{Rigid diaphragm assumption}

For the full model analysis, the rigid diaphragm assumption is often adopted to shorten the computational time. This assumption condenses all the degrees of freedom associated with the in-plane floor slab displacements. However, as mentioned in the last section, the coupling effect of slabs and beams on the walls is crucial and should be appropriately modelled. Although the inplane deformation of the transfer girder is not affected, it is essential to release the rigid diaphragm assumption on storeys above the transfer level so as not to overstate the wall shear with over-rigid floor slab connections above the transfer level. Figure 11 illustrates the distribution of SCRs for model A with an increased number of storeys using flexible diaphragms above the 


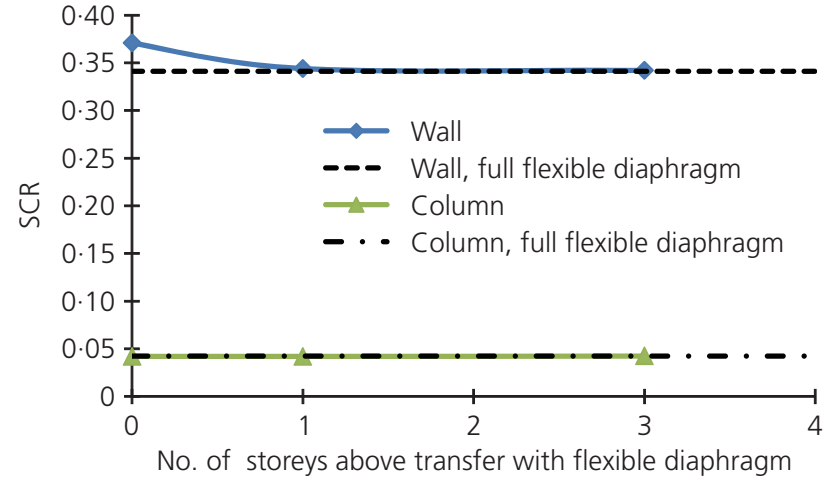

Figure 11. The variations of shear concentration ratio against the storeys with flexible diaphragms above the transfer girder for model $A$

transfer level. It can be concluded that the rigid diaphragm assumption mainly affects the upper shear walls and that the result converges quickly with the first storey being released from such an assumption.

\subsection{Stiffness degradation for structures undergoing non-linear behaviours}

The above analyses are based on elastic analysis, which should suffice to model typical structures under gravity loads with limited non-linear behaviours. However, in critical cases, such as under a rare earthquake, the effects of stiffness degradation can significantly affect the predicted deformations (ACI 318-11 (ACI, 2011)), in particular the deformation-induced stress concentration discussed in this paper. Reduced flexural and shear stiffness following a few well-developed seismic codes (ACI 318-11, (ACI, 2011); ASCE41-06 (ASCE, 2007); Eurocode 8 (CEN, 2004)) have been considered to take into account the reduction in stiffness at the yield state. Table 5 summarises the effective stiffness at the yield state adopted in this study, where $I$ denotes the gross sectional moment of inertia and $G$ is the short-term shear modulus of the section. The study finds that, although the rotation at the base of upper walls could be drastically increased by $80 \%$, the reduced stiffness of the walls can sufficiently compensate the effect, resulting in only a slight increase of about $10 \%$ in the SCRs. Comparisons of SCRs using full or yielded stiffness for model A and B are shown in Figure 12. Hence, the

Flexural stiffness (EI) Shear stiffness (GA)

\begin{tabular}{lll}
\hline Column & 0.7 & 0.5 \\
Wall & 0.6 & 0.5 \\
Slab & 0.25 & 0.5 \\
Beam & 0.35 & 0.5 \\
Transfer girder & 0.35 & 0.5
\end{tabular}

Table 5. Effective stiffness adopted for various structural members under yield state results deduced from the above analyses could be applicable to similar structures undergoing the yield state. In cases where cracking occurs only on the upper shear walls and the coupling beams under tie forces, more pronounced reductions in SCRs are obtained, which are limited to $15 \%$ and $30 \%$, respectively, for models A and B.

From the perspective of seismic design, general performance criteria such as the inter-storey drift limit at the storey just above transfer level may have to be reduced to account for the base rotations of critical walls contributing to the actual racking deformation angle (CTBUH, 2008). For instance, the cl.8.7.1 in Peer (2010) and cl.3.5.4.2.1 in LATBSDC (2011) recommend the inter-storey drifts $\leqslant 3 \%$ for a building designed to the maximum considered earthquake (MCE) level. This limit serves to prevent the non-structural components from causing any life safety hazard as well as to protect the structural components. The two codes agree that structural elements with good detailing and proper yielding mechanism are capable of providing the $3 \%$ drift limit without severe strength degradation. If the strength degradation in these elements is more severe than the shear force induced by the P-delta effect. Slight perturbation could possibly result in instability or even progressive collapse of the structures. As a considerable amount of deformation, which could be associated with 2 to $3 \mathrm{MPa}$ shear stress, is induced in the supported shear wall due to the warping of the transfer structure under gravity loads, it is reasonable to make reduction in the allowable interstorey drift limit in the seismic design for storeys in the vicinity of the transfer structure.

\subsection{Effects of sequential construction and creep}

Sequential construction has received interest in most structures requiring special attention to ensure the structural integrity is not impaired throughout the different stages of construction, particularly for bridges and high-rise structures. In view of the stress concentration effect caused by deformation of the transfer structure - a prime cause of such effect being the total dead and imposed loads of the building - the sequence of loading from each storey would not significantly alter the SCRs and BCRs. Sequential construction of each storey has been modelled in Etabs. Figure 13 compares the SCRs and BCRs for models A and $\mathrm{B}$ with and without the consideration of sequential construction. The mild differences shown in SCRs and BCRs coincide with the postulation.

Upon completion of the construction of the building, the RC creeps with time under quasi-permanent loads. Significant creep strain, equivalent to several times the initial elastic strain, could develop. According to Model Code 2010 (Fib, 2010), the timedependent strain should be accounted for in the stress calculation (cl.7.6.3) under service loads. The time-dependent strains comprise stress-dependent strains (initial and creep strains) and stress-independent strains (shrinkage and thermal strains), the latter of which are not discussed herein due to their reversible nature and cyclic fluctuations caused by seasonal rain and other 


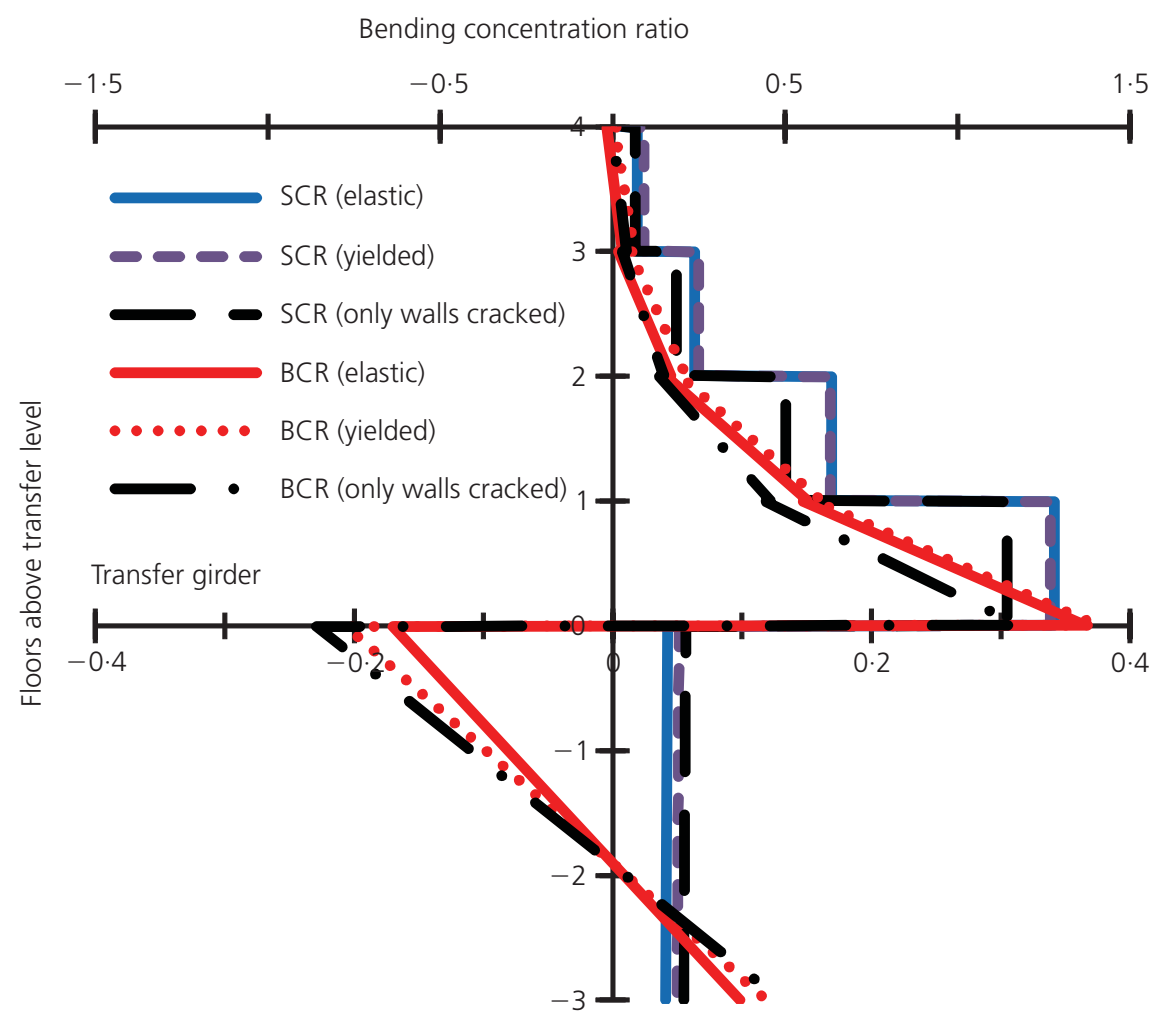

Shear concentration ratio

(a)

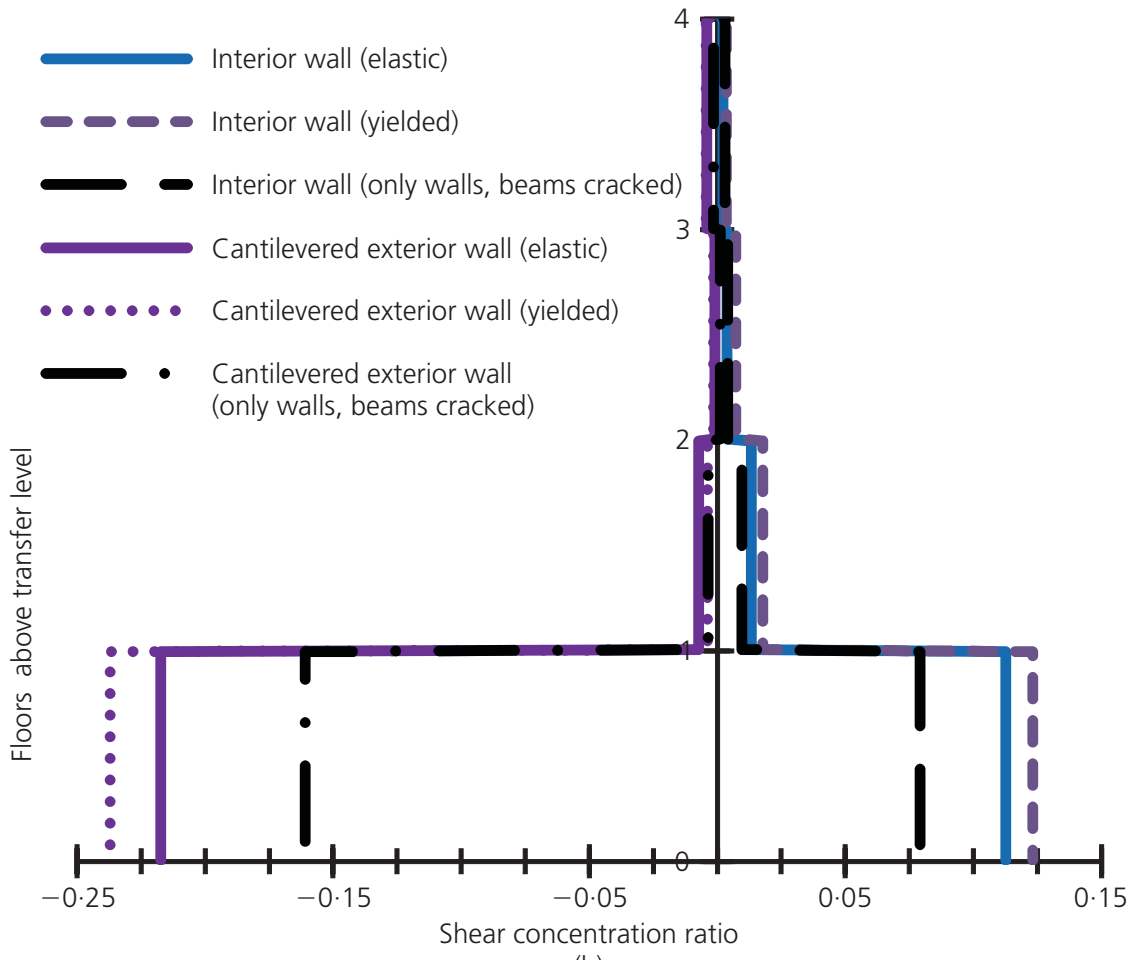

(b)

Figure 12. The comparisons of the vertical distributions of

(a) BCRs and SCRs for model A and (b) SCRs for model B under yield state or localised cracking of the upper walls and beams 


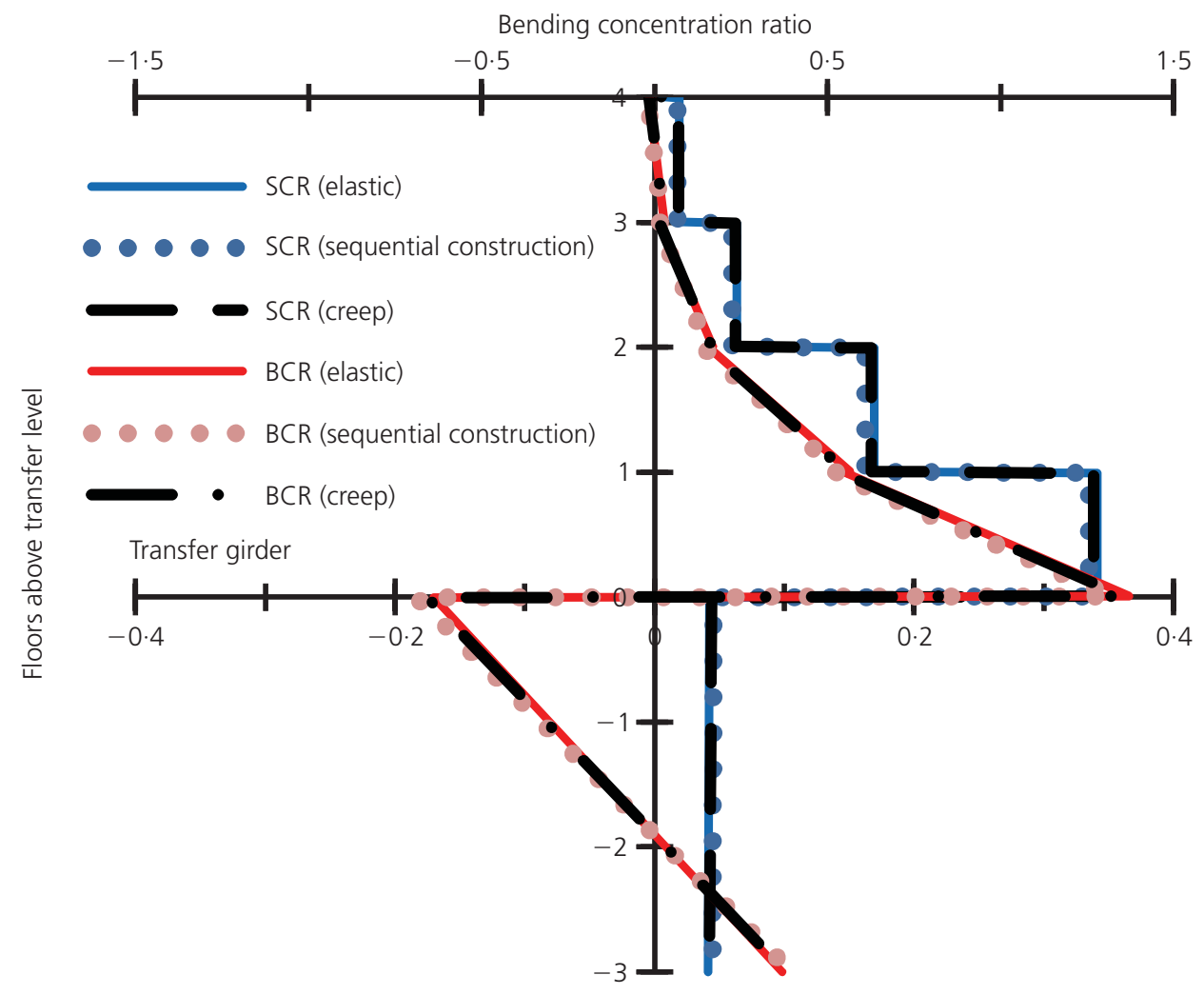

Shear concentration ratio

(a)

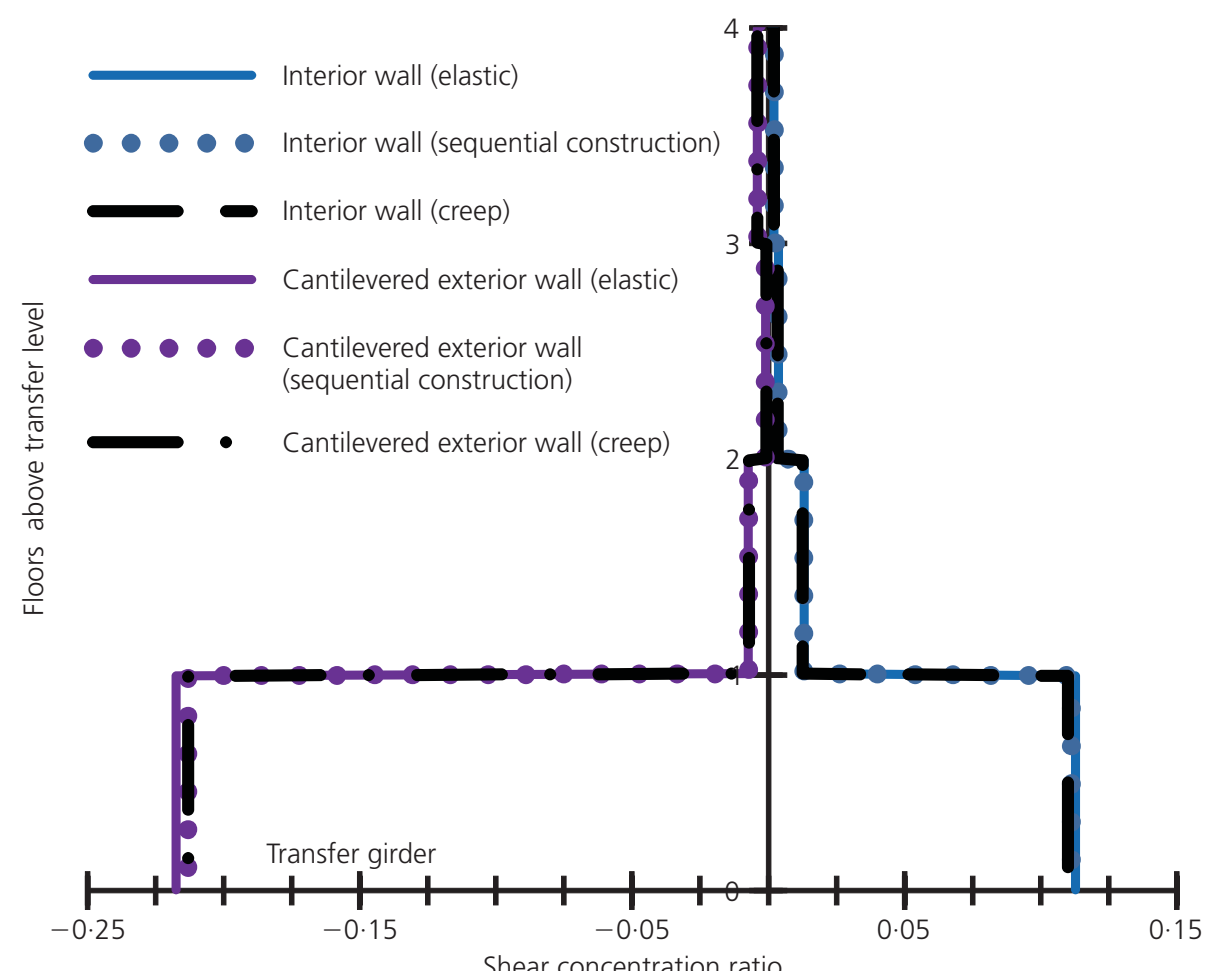

(b)

Figure 13. The comparisons of the vertical distributions of

(a) BCRs and SCRs for model A and (b) SCRs for model B with the effects of sequential construction or creeping of $R C$ 
weather conditions (Park and Paulay, 1975). In compliance with cl.5.1.9.4 in Model Code 2010 (similar creep estimations are provided in cl.3.1.4 and Annex B of Eurocode 2, BSI, 2004), the stress-dependent strains - initial and creep strains - are calculated. Assuming normal-strength cement, mean cylinder strength of concrete $\left(f_{\mathrm{c}}^{\prime}=f_{\mathrm{ck}}+8 \mathrm{MPa}\right)=44 \mathrm{MPa}$ and humidity of $70 \%$ (normal in coastal cities, e.g. Hong Kong), the creep coefficients $\varphi\left(t, t_{0}\right)$ are estimated to be 0.90 for the transfer girder and supporting columns, 0.98 for the upper walls and 1.04 for the coupling beams (Eurocode 2, BSI, 2004). The creep coefficient denotes the equivalent initial strain $\left(\varepsilon_{0}\right)$ to be developed by creeping from time $t_{0}(=365 \mathrm{~d}$, assuming the structure is fully loaded after completion) to $t$ ( $=10000 \mathrm{~d})$ under uniaxial stresses.

As the derivation of the creep strain is empirical, when neither the stochastic nature has been accounted for nor special measures have been taken to reduce the associated uncertainties, accurate structural analysis of the creep effect makes no sense (Bažant, 1988). For simplified analysis, the age-adjusted effective modulus of elasticity (AAEM) proposed by Bažant could be adopted. For brevity, the underlying concept is that the total strain of the RC component being loaded from time $t_{0}$ to time $t(=10000 \mathrm{~d})$ can simply be calculated by using the effective modulus, which is expressed as

5. $\Delta \varepsilon=\frac{1}{E^{\prime \prime}} B \Delta \sigma+B \sigma\left(t_{0}\right) \frac{\phi\left(t, t_{0}\right)}{E\left(t_{0}\right)}+\Delta \varepsilon_{0}$

Age-adjusted effective modulus

6. $E^{\prime \prime}=\frac{E\left(t_{0}\right)-R\left(t, t_{0}\right)}{\phi\left(t, t_{0}\right)}$

where $\sigma$ is the applied stress tensor, $\varepsilon$ is the strain tensor, $E$ is the short-term elastic modulus, $B$ is the compliance tensor and $\Delta$ denotes the change of strain or stress from time $t_{0}$ to $t$. The ageadjusted effective modulus depends on a linear algebraic relaxation function $R\left(t, t_{0}\right)$. This modulus can be closely approximated by Equation 7 assuming the ageing coefficient $\chi\left(t, t_{0}\right)=1$.

Effective modulus for a modified creep coefficient

7. $E^{\prime \prime}=\frac{E\left(t_{0}\right)}{\left[1+\chi\left(t, t_{0}\right) \phi\left(t, t_{0}\right)\right]}$

For simplicity, the applied stress is assumed to be invariant: that is, the strain recovery due to stress relaxation is ignored. This assumption is verified later. In addition, the effective modulus that accounts for the effect of creep strain has been adopted in the Etabs model. When creep strains are developed to encompass whole structures, the effective moduli of $0.50 \mathrm{E}$ for upper walls, beams and slabs, and $0.53 E$ for the supporting columns and the transfer girder, are estimated from Equation 7. They differ mainly due to the effective thicknesses that constrain the moisture loss resulting in lower creep strain. Figure 13 depicts the SCRs and BCRs of models A and B when the creep strain is considered. The reductions in SCRs and BCRs are less than 5\%, which is modest. This is attributed to compensation between the reduced lateral thrust by the coupling beam and the increase in the base rotations of the walls. The slight variations of SCRs and BCRs justify the invariant stress assumption in deriving the effective moduli.

As high compressive stress would result in high and almost unpredictable creep, a non-linear model should be used for creep assessment when concrete compressive stress $>0.4 f_{\mathrm{c}}^{\prime}$ under service loads (cl.7.6.3.3 Fib, 2010). The current model under examination is subjected to an axial load ratio $\approx 0.2$ under service loads (i.e. load factor $=1 \cdot 0$ ). The stress at the extreme compressive fibre could be close to or exceed $0.4 f_{\mathrm{c}}^{\prime}$ if the bending stress (if $\mathrm{BCR} \geqslant 1$ ) is considered. Yet, the above linear creep analysis defines the lower-bound benefit due to creep. A larger reduction in SCRs could be obtained if a detailed non-linear creep model was used. However, this may be justifiable for a realistic project in which actual structural layouts are also considered in detail.

\subsection{Mitigating measures}

To reduce the significance of the shear concentration effect on the upper shear walls, rather than changing the column layout to minimise the support offset, which is often constrained by various architectural requirements, other available solutions are discussed as follows.

(a) Use of late-cast slabs: As the shear concentration effect is attributable to the displacement of the supported walls and is transmitted through the coupling slabs and beams, the problem can be resolved if the walls can displace freely under gravity loads from full construction before the restraining slabs and beams are cast. Figure 14 illustrates the reduction in the SCR and BCR for model A with increased storeys using late-cast slabs. A significant amount (up to 30-40\%) of

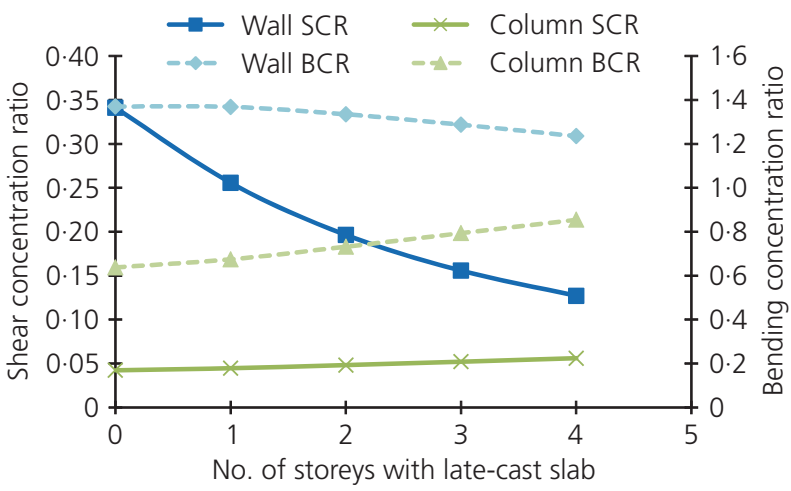

Figure 14. The variations of shear and bending concentration ratios against the storeys with a late-cast slab above the transfer girder for model $\mathrm{A}$ 
the shear stress on the upper shear walls can be reduced by having the first and second floors use late-cast slabs. However, the reduction in the BCR is less than $10 \%$, which is insensitive to this measure. This is most likely due to the balanced effect between the increased moment arm and the reduced shear loads on walls with late-cast slabs.

(b) Increase in the depth of the transfer girder: Increasing the depth of the transfer girder could effectively control the bending and shear deformations of the transfer girder. Figure 15 shows the variations of the SCR and BCR for model A and $\mathrm{B}$ against increased depth of the transfer girder. To reduce $50 \%$ of the SCR, the depth of the transfer girder is increased from $2 \mathrm{~m}$ to $6 \mathrm{~m}$ for model $\mathrm{A}$ (span-to-depth ratio from 5 to $1 \cdot 7$ ), whereas model B requires only half the depth, which is $3 \mathrm{~m}$ (span-to-depth ratio from 1.5 to 1 , considering the span of the cantilever transfer girder). The more sensitive result revealed in model B is likely attributable to the smaller span length and the bending and shear deformations of the transfer girder is counter-balanced by the eccentrically supported interior wall and cantilevered exterior wall on either side of the supporting column. A deeper transfer girder has other merits, such as alleviating the local shear stress

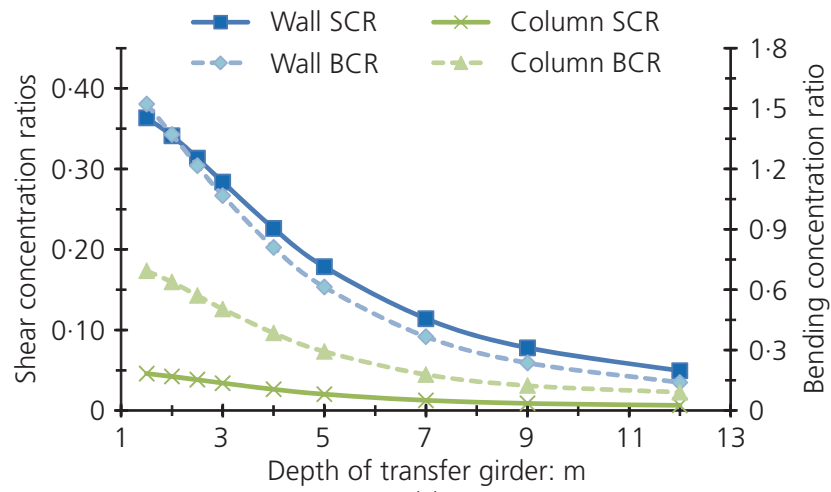

(a)

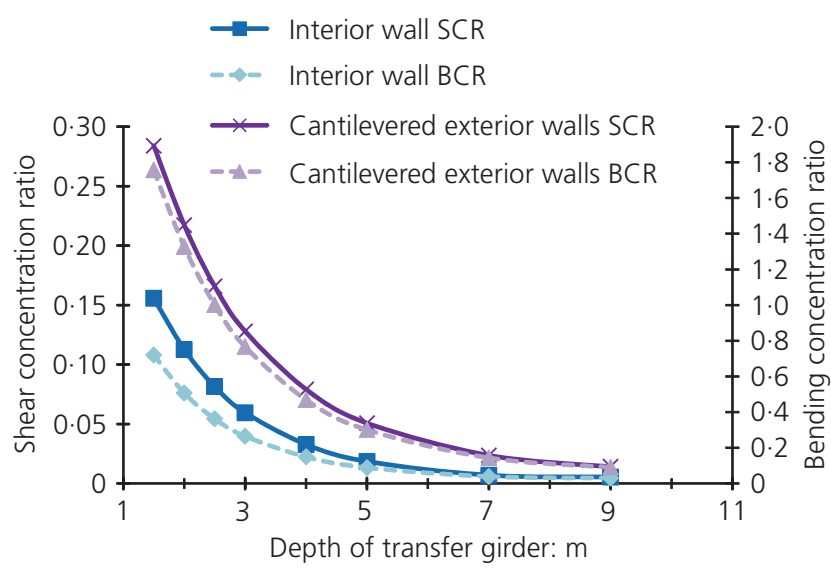

(b)

Figure 15. The variations of shear and bending concentration ratios against the depth of the transfer girder for (a) model $A$ and (b) model B induced within a wall and the shear concentration owing to lateral loads by having a more robust transfer structure.

The remedial measures above are only for reference. As the mechanism is well understood, the design philosophy is to reduce the lateral stiffness of the coupled shear walls and/or increase the vertical stiffness of the transfer girder; hence, this approach can restrain the bending and shear deformations of the transfer girder and the shear loads inflicted on the supported walls. More alternatives could be available depending on the site conditions, such as $(a)$ shortening the wall length by using more wall panels, in which discrete and slender wall segments reduce the lateral stiffness and hence the shear loads induced under a constant displacement; $(b)$ using higher grade concrete for a few storeys around the transfer level, the maximum shear capacity can be increased by $20-30 \%$ by changing from $\mathrm{C} 45$ to $\mathrm{C} 60$ concrete, depending on the code provisions; and (c) increasing the thickness of shear walls above the transfer structure. Although the SCR and $\mathrm{BCR}$ are insensitive to the change in the axial normal stress, the absolute shear stress is linearly proportional to the normal stress on the wall. Figure 16 presents the variations of the SCRs and the average normal stress $\left(\sigma_{N, \text { total }}\right)$ with various shear wall thicknesses.

\section{Conclusion}

Owing to the critical shear concentration effect on shear walls above column-supported transfer girder structures, a critical proportion of the maximum allowable shear strength (30-50\%) could be consumed solely due to gravity loads. Two-dimensional elastic models effectively illustrate the proposed shear concentration mechanism of the shear walls above a deformed transfer girder under in-plane gravity loads. Despite reduction in shear by 15 to $30 \%$ with localised cracking of the upper shear walls, almost unchanged shear loads revealed on structures with yielded stiffness or under long-term creeping prove the applicability of this study to those conditions.
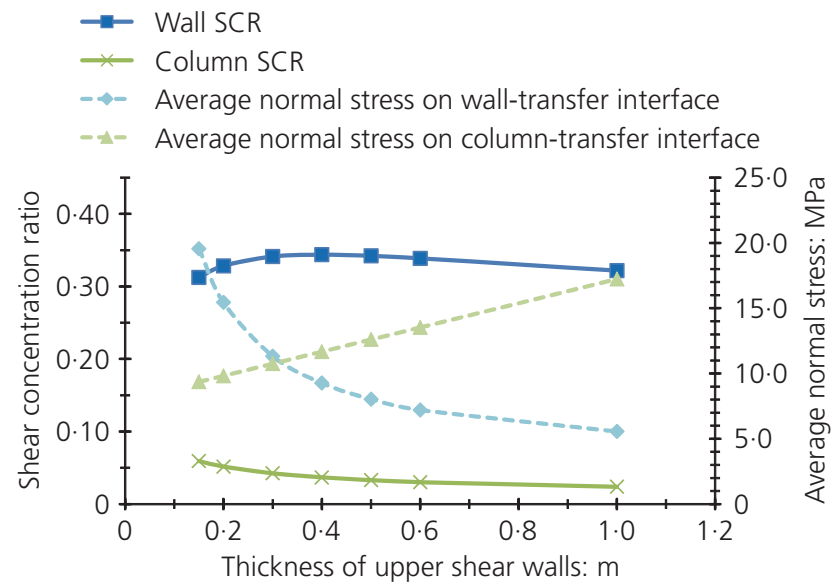

Figure 16. The variations of shear concentration ratios and average normal stresses against the thickness of the upper shear walls for model A 
To appropriately account for the shear concentration effect, not only does special attention have to be placed on modelling techniques, such as the release of the rigid diaphragm assumptions above the transfer level and the limit of simplified models by equivalent gravity loads, but it is also crucial to optimise the structural layout to minimise the bending and shear deformations of transfer girders and hence the difference in base rotations between adjacent shear walls. If, due to architectural constraints, optimised support conditions are not possible, other remedial measures are proposed, such as using late-cast slabs, transfer girders with increased depth, segmented and thicker upper shear walls, and concrete of higher grade for critical regions.

\section{REFERENCES}

ACI (American Concrete Institute) (2011) ACI 318-11: Building code requirements for structural concrete and commentary. ACI, Farmington Hills, MI, USA.

ASCE (The American Society of Civil Engineers) (2007) ASCE 41-06: Seismic rehabilitation of existing buildings. ASCE, Reston, VA, USA.

Bažant ZP (1988) Mathematical Modeling of Creep and Shrinkage of Concrete. Wiley, New York, NY, USA, Rilem TC69 Committee.

BSI (1997) BS8110: The structural use of concrete: Part I, code of practice for design and construction. BSI, London, UK.

BSI (2004) BS EN 1992-1-1: 2004: Eurocode 2: Design of concrete structures - Part 1: General rules and rules for buildings. BSI, London, UK.

CEN (European Committee for Standardisation) (2004) EN 1998-1: 2004: Eurocode 8: Design of structures for earthquake resistance - Part 1: General rules, seismic actions and rules for buildings. CEN, Brussels, Belgium.

Choo BS and Li GQ (1997) Structural analysis of multi-stiffened coupled shear walls on flexible foundations. Computers and Structures 64(1-4): 837-848.

CSI (Computers and Structures, Inc.) (2005) CSI Analysis Reference Manual For SAP2000, ETABS, and SAFE. CSI, Berkeley, CA, USA.

Coull A (1971) Interaction of coupled walls with elastic foundations. American Concrete Institute 68(6): 461-456.

Coull A and Chantaksinopas B (1974) Design curves for coupled shear walls on flexible bases. Proceedings of the Institution of Civil Engineers 57(4): 595-618.

CSA (2004) CSA, A23.3-04: Design of concrete structures. Canadian Standards Association (CSA), Ontario, Canada.

CтBUH (2008) Recommendations for Seismic Design of High-Rise Buildings. Council of Tall Buildings and Urban Habitat (CTBUH), Chicago, IL, USA.

Fib (International Federation for Structural Concrete) (2010) Model Code 2010 Vol 1 and Vol 2. Ernst \& Sohn, Germany, fib Bulletin No. 55 and 56. Fib, Lausanne, Switzerland, Fib Special Activity Group 5, DCC Document Competence Center Siegmar Kästl e. K.

Kuang JS and Zhang Z (2003) Analysis and behaviour of transfer plate-shear wall systems in tall buildings. Design of tall and special buildings. The Structural Design of Tall and Special Buildings 12(5): 409-421.

LATBSDC (Los Angeles Tall Buildings Structural Design Council) (2011) An Alternative Procedure for Seismic Analysis and Design of Tall Buildings Located in the Los Angeles Regions. LATBSC, Los Angeles, CA, USA.

Liu K and Wang L (2009) Crack control during construction of high-rise RC transfer structures. Sichuan Building Materials 35(3): 55-55 (in Chinese).

Macleod IA and Green DR (1973) Frame idealization for shear wall support systems. The Structural Engineer, 51(2): 71-74.

Man CF (2010) Cracking in high-rise RC transfer structures. Modern Business Trade Industry 16(19): 379-380 (in Chinese).

Nadjai A and Johnson D (1998) Elastic and elasto-plastic analysis of planar coupled shear walls with flexible bases. Computers \& Structures 68(3): 213-229.

Peer (Pacific Earthquake Engineering Research Center) (2010) Guidelines for Performance-Based Seismic Design of Tall Buildings. The TBI Guidelines Working Group, Berkeley, CA, PEER Report 2010/05.

Park R and Paulay T (1975) Reinforced Concrete Structures. Wiley, New York, NY, USA.

SNZ (Standards New Zealand) (2006) NZS 3101: Part 1: 2006: Concrete structures standard Part 1 -The design of concrete structures. SNZ, Wellington, New Zealand.

Stafford Smith B and Riddington JR (1977) The composite behaviour of elastic wall-beam systems. Proceedings of the Institution of Civil Engineers 63(2): 377-391.

Su RKL, Chandler AM, Lee PKK, To A and Li JH (2003) Dynamic testing and modelling of existing buildings in Hong Kong. The HKIE Transactions 10(2): 17-25.

Su RKL and Cheng MH (2008) Earthquake induced shear concentration in shear walls above transfer structures. The Structural Design of Tall and Special Buildings 18(6): 657-671.

Toutanji HA (1997) The effect of foundation flexibility on the interaction between shear walls and frames. Engineering Structures 19(12): 1036-1042.

Vuddandam RB, Toutanji H and Rodgers R (2013) Approximate solutions to coupled shear walls on fixed and flexible foundations. Modern Applied Science 7(4): 1-16.

\section{WHAT DO YOU THINK?}

To discuss this paper, please email up to 500 words to the editor at journals@ice.org.uk. Your contribution will be forwarded to the author(s) for a reply and, if considered appropriate by the editorial panel, will be published as a discussion in a future issue of the journal.

Proceedings journals rely entirely on contributions sent in by civil engineering professionals, academics and students. Papers should be 2000-5000 words long (briefing papers should be 1000-2000 words long), with adequate illustrations and references. You can submit your paper online via www.icevirtuallibrary.com/content/journals, where you will also find detailed author guidelines. 